National

\title{
NAS-NS
}

3108

Academy

of

Sciences

National Research Council

NUCLEAR SCIENCE SERIES

Radiochemical Techniques

\section{Application \\ of Distillation Techniques \\ to Radiochemical \\ Separations}

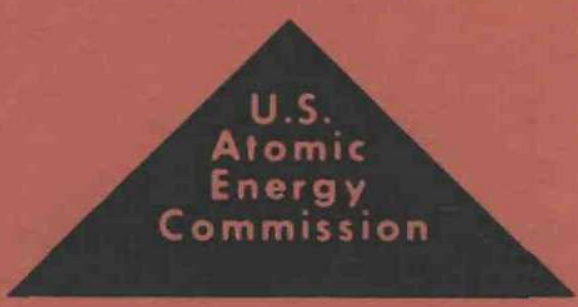




\section{COMMITTEE ON NUCLEAR SCIENCE}

S. K. Allison, Clatimant University al Chicago
R. D. Evans, Vice Chairinam

Mass. Institute of Technology

Lewis slack, Secretary

National Research Council

E. C. Anderson

Los Alamos Bo1. Labocatory

N. E. Ballor

U.S. Naval Radiological Defense Laboratory

C. J. Borkowski

Oak Ridge Nat!, Laboratory

Robert G. Cochran

A 4 M College of Texas

Ugo Fano

National Bureau of Standards
Herbert Goldstein

Columbia University

Bernd Kahn

Taft Sanitary Engineering Center

\section{J. J. Nicksan}

Memorial Hospital (New York)

R. L. Platzman

Argonne National Laboratory

D. M. Van Patter

Bartol Research Foundation

\section{George W. Wetherill \\ University of Catifornia (Los Angeles)}

\section{LIAISON MEMBERS}

Paul C. Aebersold

Atomic Bnerby Commission

Joseph E. Duval

Air Force Office of Scientifie Research
Jerome Fregean

Office of Naval Research

J. Howard MoMillen

National Science Foundation

\section{SUBCOMMITIEE ON RADIOCHEMISTRY}

N. B. Ballou, Chaimmar

U. S. Naval Radiological Defense Laboratory

G. R. Choppin

Florida State University

H. M. Clark

Rensselaer Polytechnic Instifute

R. M. Diamond

Lawrence Radiation Laboratory

A. W, Fairhall

University of Washington

Jerome Hudis

Brockbaven National Laboratory
J. D. Knight

Los Alamos Scientific Laborator;

\section{J; M. Nielsen}

General Electric Company (Rdichland)

G. D. O'Kelley

Oak Ridge National Laboratory

R. P. Sehuman

Atomic Energy Division

Phillips Petrofeum Company (Idaho Falis)

E. P. Steinberis

Argonne National Laboratory

P. C. Stevenson

Lawrence Radiation Laboratory

D. N. Sundermar

Battelle Memorial Institute

\section{CONSULTANT}

J. W. Winchester

Massachusetts Institute of Fechnology 


\section{DISCLAIMER}

This report was prepared as an account of work sponsored by an agency of the United States Government. Neither the United States Government nor any agency Thereof, nor any of their employees, makes any warranty, express or implied, or assumes any legal liability or responsibility for the accuracy, completeness, or usefulness of any information, apparatus, product, or process disclosed, or represents that its use would not infringe privately owned rights. Reference herein to any specific commercial product, process, or service by trade name, trademark, manufacturer, or otherwise does not necessarily constitute or imply its endorsement, recommendation, or favoring by the United States Government or any agency thereof. The views and opinions of authors expressed herein do not necessarily state or reflect those of the United States Government or any agency thereof. 


\section{DISCLAIMER}

Portions of this document may be illegible in electronic image products. Images are produced from the best available original document. 


\title{
Application of Distillation Techniques to Radiochemical Separations
}

\author{
JAMES R. DeVOE \\ National Bureau of Standards \\ Washington, D. C.
}

August 1962

Subcommittee on Radiochemistry

National Academy of Sciences-National Research Council 


\section{FOREWORD}

The Subcomittee on Radiochemistry is one of a number of subcommittees working under the Committee on Nuclear Science within the National Academy of Sciences - National Research Council. Its members represent government, industrial, and university laboratories in the areas of nuclear and radiochemistry.

The Subcommittee has concerned itself with the preparation of publications, nuclear education, special oroblems, and sponsorship of symposia on selected current topics in nuclear and radiochemistry. A series of monographs on the radiochemistry of essentially all the clements and on radiochemical techniques is being published. Initiation and encouragement of publication of articles on nuclear education in the areas of chemistry have occurred, and development and improvement of certain educational activities (e.g., laboratory and demonstration experiments with radioactivity) have been encouraged and assisted. Radioactive contamination of reagents and materials has been investigated and specific recommendations made.

This series of monographs has resulted from the need for comprehensive compilations of nuclear and radiochemical information. Each monograph collects in one volume the pertinent information required for radiochemical work with an individual element or with a specialized technique. The U.S. Atomic Energy Commission has sponsored the printing of the series.

Comments and suggestions for further publications and activities of value to persons working with radioactivity are welcomed by the Subcomnittee.

N. E. Ballou, Chairman

Subcomittee on Radiochemistry 


\section{ABSTRACT}

The use of vacuum distillation of inorganic compounds and metals for radiochemical separations is reviewed. A brief description of the experimental apparatus which is most often used for the distillation is outlined. Advantages and disadvantages of the various techniques are discussed. Detailed separation procedures are described for wet chemical distillation separations as well as for separations of daughter radioactivity from target materials by direct heating of the target. 


\section{CONTENTS}

\section{Page}

I. Introduction 1

II. The Distillation Process for Radiochemical Separations

A. List of General References on Distillation 2

B. Types of Apparatus 2

1. Carrier vapor distillation train 2

2. Simple one plate distillation 3

C. Expected Purity for the One Plate Distillation 7

D. Future Applications 9

III. Radiochemical Distillation Procedures 10

A. Hydrogen 10

B. Rare Gases 10

C. Carbon, Nitrogen and Oxygen II

D. Halogens 11

E. Alkali Metals II

F. Silicon 12

G. Phosphorous 12

H. Sulfur 12

I. Alkaline Earths, Rare Earths and Yttrium 12

J. Vanadium 12

K. Chromium 12

L. Manganese 13

M. Germanium, Arsenic, Antimony and Tin 13 
N. Selenium and Tellurium 15

0. Ruthenium, Osmium, Technetium, Rhenium 16

P. Rhodium and Silver 16

Q. Cadmium 18

R. Indium 20

S. Gold 21

$\begin{array}{ll}\text { T. Mercury } & 21\end{array}$

U. Lead 24

v. Bismuth 25

W. Polonium 25

x. Astatine 25

Y. Uranium 25

References 26 


\title{
Application of Distillation Techniques to Radiochemical Separations
}

\author{
JAMES R. DeVOE \\ National Bureau of Standards \\ Washington, D. C.
}

I. INTRODUCTION

An adequate radiochemical separation can be defined as a separation of the radioisotopes of a given element from those of a group of other elements so that maximum purity and yield are obtained in a time which is short compared to the half-1ife of the desired radioisotope of the element which is separated. The distillation technique has been used less often for radiochemical separations than methods such as extraction or ion exchange; however, in some instances distillation proves to be the best method.

It is the purpose of this report to indicate how well distillation techniques satisfy the requirements of radiochemical separations, and to point out which elements can be conveniently separated by distillation.

In recent years some consideration has been given to the preparation of carrier-free sources by the distillation technique. Therefore, a number of these separations are discussed.

It is important in a report of this type to discuss the disadvantages as well as the virtues of the method, so a few pages have been devoted to the difficulties that occur. In some of the separations 
it will be apparent that the technique is cumbersome if only because of the length of time that the separation requires.

This author is indebted to all of the other authors of the NAS-NRC Nuclear Science Monographs on the radiochemistry of the elements, since frequent reference has been made to the detailed distillation procedures 1 isted in those reports.

II. THE DISTILLATION PROCESS FOR RADIOCHEMICAL SEPARATIONS

\section{A. List of General References on Distillation}

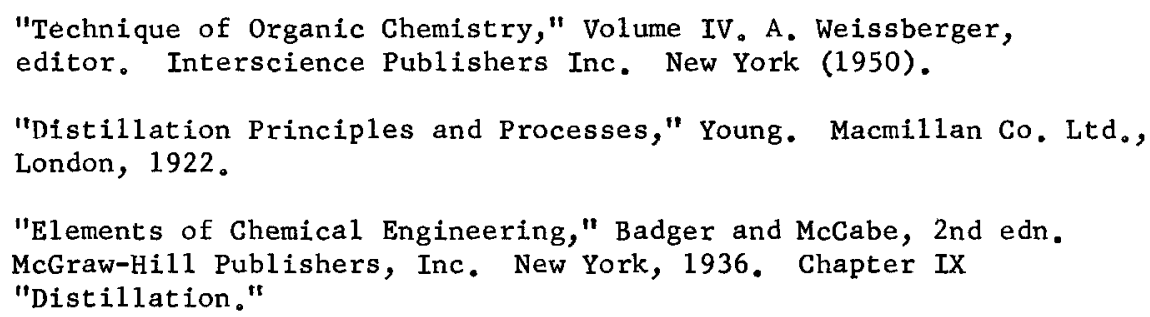

The distillation technique proves to be suitable for many radiochemical separations, since a large number of variables in the distillation process, e.g., pressure, temperature, time of distillation, vapor condensing surface, etc., allows modification of the method to enhance the separation.

In order to clarify the description of the radiochemical distillation separations which have been reported, the processes have been grouped into two classes; the carrier vapor distillation train, and the simple one plate distillation.

\section{Carrier Vapor Distillation Train}

A11 of the radiochemical methods in this class utilize an apparatus that can be described as follows: The distillation flask containing the solution to be separated is connected with a ground glass joint through which is passed a tube for introducing reagents and/or a carrier gas. The outlet tube which also passes through the joint is terminated in a male connector of a ball and socket joint. The ball and socket joint facilitates assembly of a multi-flask distillation train. 
The vapor collecting flasks are made in a similar manner. The inlet tube is allowed to extend into the flask so that its tip extends below the collecting fluid. Any number of these flasks can be connected together to allow separation by selective condensation in each collecting flask through choice of the collecting medium. The vapor collecting flasks may be arranged to allow either heating or cooling as desired. Quite often it is advisable to pass an inert gas through the distillation train to act as a carrier for the radioelement. It is best to draw the gas through the system so as to maintain the internal pressure slightly below that outside of the apparatus. This reduces leakage which could result in radioactive contamination.

Most often the train type of distillation requires the addition of usually ten milligram amounts of the naturally-occurring element to the distillation flask before distillation. This acts as an isotopic carrier for the radioactive isotope of the element to be separated.

An excellent general study on the relative volatilities from various types and compositions of acid solutions of many elements has been done by Hoffman and Lunde11 (22).

\section{Simple One Plate Distillation}

In its simplest form the apparatus consists of a furnace and a vapor collector. Figure 1 illustrates a particular system which uses the simple one plate distillation. The surface area of the collector is restricted to a few $\mathrm{cm}^{2}$ so that the collector itself upon which the radioisotope is collected may be counted.

In order to maximize the yield of the distillation, the collector is placed as close to the furnace as is possible without causing excessive heat transfer through the radiative process. Such distillations are carried out in vacuum to reduce the dispersion of vapor and further optimize the yield. It should be realized that in vacuum the vaporization process is often a sublimation; however, for this general discussion the term distillation will be used. Stockendal (60) 


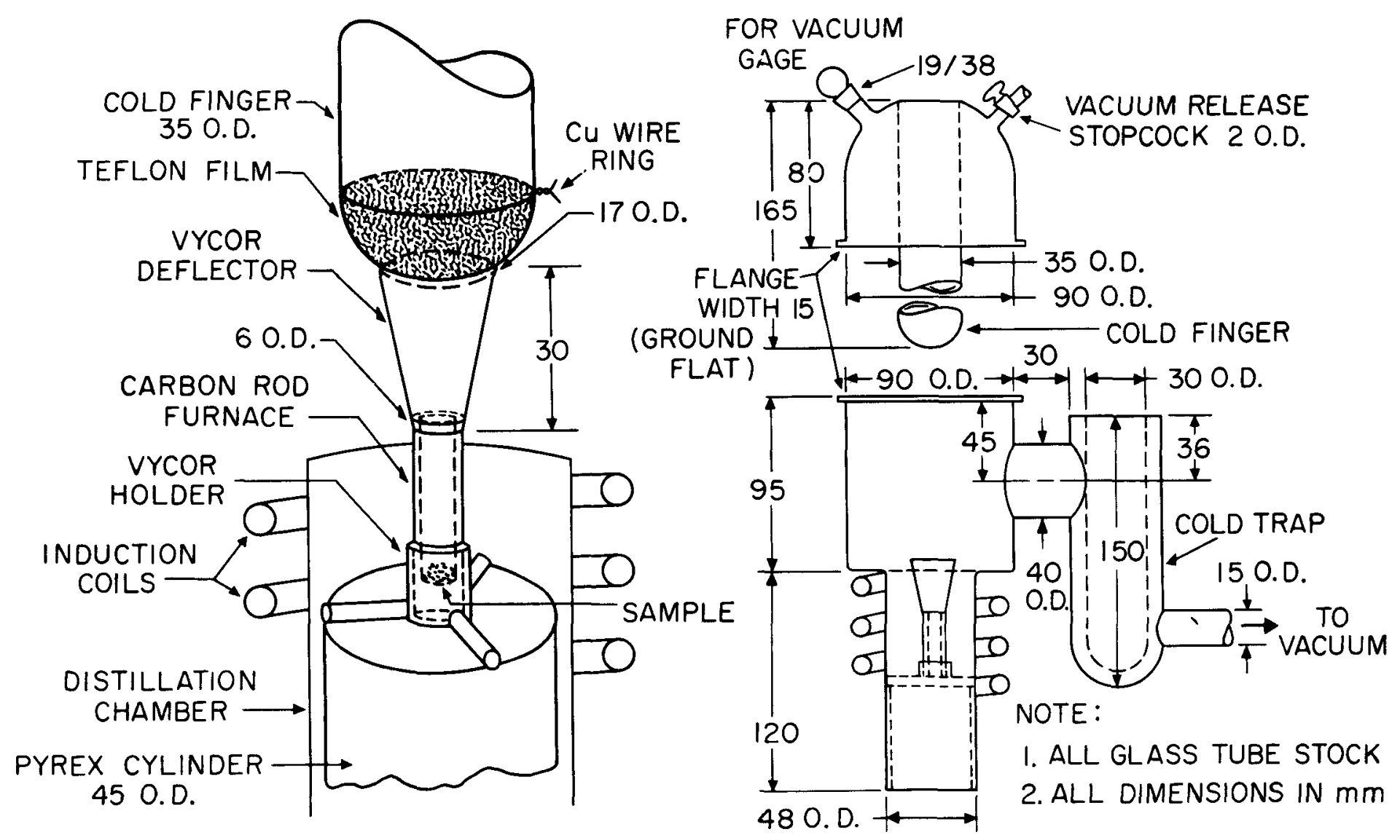

Fig. 1-Apparatus for vacuum distillation showing furnace with collector in place (left) and the complete apparatus showing location of furnace (right). 
as well as the author (12) has found that a heated deflector in the shape of a cone directs the vapor toward the collecting device to give a more satisfactory yield.

Many types of furnaces have been described $(10,17,59)$. The most common method of heating is with a spiral tungsten filament shaped to form a cone. Quite often a ribbon is used so that the sample to be heated can be placed on the ribbon. The filament is then heated by passing an electrical current through it.

Induction heating proves to be a successful method. It is particularly attractive when a vacuum apparatus is used since the induction coil need not enter into the vacuum. A carbon cruciblefurnace heated by induction has been used for some separations, $(12,21)$. Care must be taken with any furnace to ascertain that the radioisotopes to be distilled do not form a non-volatile compound with the furnace material. Carbides may be formed in a carbon furnace.

The choice of material which is used to collect the vapor is of great importance. It is possible to increase the selectivity of a separation by proper selection of the composition of the collector to improve the efficiency of collection of one over that of another radioelement. Even though considerable care is given to the formation of the surface of the collector it may be assumed that many gases are adsorbed on its surface even in a vacuum. The presence of an oxide film, adsorbed gases, or an otherwise unclean surface on the collector usually diminishes the collection efficiency. Good discussions of these collection problems are given in references $(3,8,10,15,17$, $18,36,43,44,54)$.

Thin plastic films are used as a collector, since this allows the deposited vapor to be readily removed for measurement of the radiation of the deposited radioisotopes. The back scattering of the radiation from a film of this type is minimized. Most of the film collectors are cooled by using a cooled backing surface such as the 
outside of a liquid nitrogen cold trap upon which the film is fixed. Merines (40) discusses the formation of homogeneous counting samples by vacuum distillation, and Widmer and Kirsch (64) have evaporated radioisotopes directly onto the surface of solid state radiation detecting devices. Parker (45) describes an apparatus for the preparation of thin beta particle counting filns. Holland (21) has prepared a comprehensive text on the technique of vacuum deposition of thin films. Yaffe (66) presents an excellent review of thin counting films. Quite often a radioisotope which has been produced in a nuclear reaction with a target material can be separated in a one step process by simply heating the target material. Since the radioisotope is free of a large quantity of the stable element (usually called carrier-free), self-absorption of the radiation is minimized. Another advantage is that the distillation technique provides a very even distribution of the radioisotope on the collector.

Many of the designs for the distillation apparatus incorporate a means for detecting the radiation from the separated radioisotope soon after the deposition has ended (17, 45, 53). Such an apparatus usually incorporates a shielded detector within the system so that the collector does not have to be removed from the vacuum. With this method, distillation proves to be a useful technique for measuring radioisotopes with very short half lives (e.g., 1 second).

At present it has been found to be difficult to reproduce a given yield in a carrier-free separation. This is probably due to difficulty in the collection of the vapor. In addition, the yields are often low. This can be due to lack of complete volatilization as wel1 as lack of quantitative vapor collection. Fortunately for most applications, where the radioisotope is used for study of its radiation, the yields have been sufficient. The high degree of purity of the separated radioisotope makes the simple one plate distillation method particularly suited to the carrier-free separation of products 
from an irradiated target.

There has been much progress in the separation of macro amounts of substances from multicomponent systems. Satisfactory separations have been obtained through the use of a fractional sublimation technique which is analogous to the zone melting technique and has been called the vapor zone refining method $(39,55,61,63)$. The apparatus consists of a long cylindrical evacuated tube with the charge at one end. The area of the tube containing the charge is heated to sublime the volatile components. These components condense on the sides of the tube which are not heated. The heating element is then moved progressively down the tube resulting in a repetitive sublimation and increasing fractionation of the components. Another approach involves the repetitive evaporation and condensation of material on moving belts (7). Heat is applied from a stationary heating element over which a belt containing the substance to be sublimed is passed. A moving collector belt passes over a cooled portion above the heating element. Fractionation is accomplished by increasing the temperature and moving the collector and heating belts.

\section{Expected Purity for the One Plate Distillation}

Except in the simplest of cases it is very difficult to determine beforehand how satisfactory a separation by distillation will be. In the interest of indicating how the terms which are most often used in discussing radiochemical separations relate to terms of more common usage in the physical chemistry of the process, a few relationships will be given.

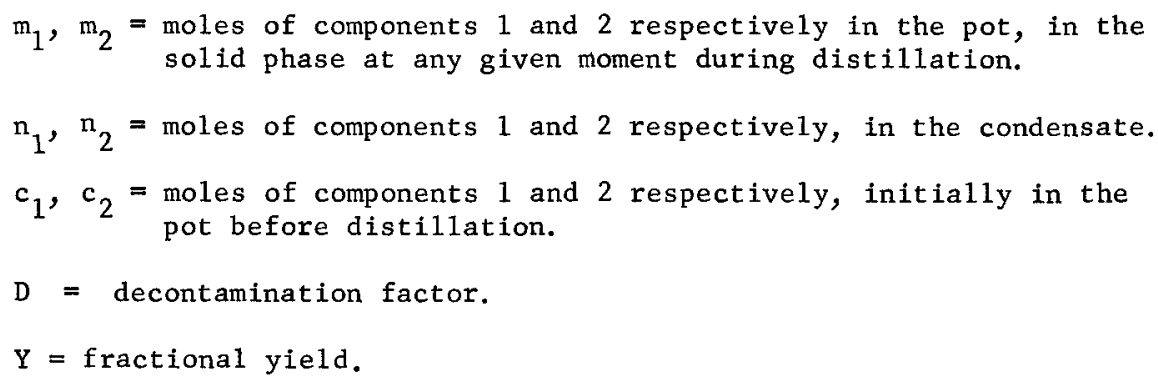
solid phase at any given moment during distillation. pot before distillation.

D = decontamination factor.

$\mathrm{Y}=$ fractional yield. 
$\alpha=$ relative volatility.

If it is desired to separate the more volatile component 1 from component 2, using a single plate batch type of distillation (or sublimation), the decontamination factor from component 2 is often indicated in radiochemical separations to be $D=\frac{A_{2}^{\circ}}{A_{2}^{1}}$, while the yield for component 1 is $Y=\frac{A_{1}^{\prime}}{A_{1}^{O}}$, where $A_{2}^{o}$ equals total radioactivity (counts per minute) of the contaminant present with the desired radioisotope before separation, $A_{2}^{\prime}$ equals total radioactivity (counts per minute) of the contaminant which separates with the desired radioisotope, $A_{1}^{0}$ equals total radioactivity (counts per minute) of the desired radioisotope before separation, $A_{1}^{\prime}$ equals total radioactivity (counts per minute) of the desired radioisotope after separation. Since the specific activities of each component are not likely to be altered during the distillation (neglecting isotope effects),

$$
\mathrm{D}=\frac{\mathrm{S}_{2} \mathrm{~A}_{2}^{\mathrm{O}}}{\mathrm{S}_{2} \mathrm{~A}_{2}^{\mathrm{I}}}=\frac{\mathrm{c}_{2}}{\mathrm{n}_{2}} \quad \mathrm{Y}=\frac{\mathrm{S}_{1} \mathrm{~A}_{1}^{\prime}}{\mathrm{S}_{1} \mathrm{~A}_{1}^{\mathrm{O}}}=\frac{\mathrm{n}_{1}}{\mathrm{c}_{1}}
$$

where $s_{1}, s_{2}$ are the specific activities in disintegrations or counts per unit time per unit weight of the element or component.

The term "relative" volatility which is used to define the degree of separation expected is defined as $\alpha=\frac{\overline{\mathrm{P}}_{1} \mathrm{X}_{2}}{\overline{\mathrm{P}}_{2} \mathrm{X}_{1}}$, where $\overline{\mathrm{P}}_{1}, \overline{\mathrm{P}}_{2}$ are the partial pressures of components 1 and 2 which have mole fractions $x_{1}$ and $x_{2}$ in the distillation pot. When Dalton's law of partial pressures can be applied $\frac{\overline{\mathrm{P}}_{1}}{\overline{\mathrm{P}}_{2}}=\frac{\mathrm{Z}_{1}}{\overline{\mathrm{Z}}_{2}}$, where $\mathrm{z}$ is the mole fraction in the vapor. Substituting into the equation for $\alpha$ gives

$$
\alpha=\frac{z_{1} x_{2}}{z_{2} x_{1}}=\frac{n_{1} m_{2}}{n_{2} m_{1}}
$$

If Raoult's law applies to the vapor, $\overline{\mathrm{P}}_{1}=\mathrm{X}_{1} \mathrm{P}_{1}, \overline{\mathrm{P}}_{2}=\mathrm{X}_{2} \mathrm{P}_{2}$ and $\alpha=\frac{\mathrm{P}_{1}}{\mathrm{P}_{2}}$ where $P_{1}, P_{2}$ are the vapor pressures of the pure components. Therefore $\alpha$ is a constant. At the beginning of a distillation where $n_{1} \ll c_{1}$, $n_{2} \ll c_{2}, \alpha=\frac{c_{2} n_{1}}{c_{1} n_{2}}=D Y$. As the distillation progresses the product DY decreases according to the expression $\alpha^{\prime}=\mathrm{DY}=\frac{\mathrm{Y}}{1-(1-\mathrm{Y})^{1 / \alpha}}$.

Since a better separation is obtained from a distillation which has 
a higher $\alpha^{\prime}$ there is an optimum yield which must depend upon the purposes of the separation. If a high purity is desired the yield must be sacrificed.

The above is a considerable oversimplification of a practical distillation since the formation of non-ideal solutions and non-ideality of the vapor can greatly alter the separation from that indicated above. Even less can be predicted about the separations obtained with carrierfree systems than with macro systems. Nevertheless, one might be inclined to be optimistic about the uses of the method when one considers that vapor pressures of many substances, e.g. metals, differ in magnitude by many powers of ten.

\section{Future App1ications.}

Even though new methods are found each year for the separation of compounds from aqueous solution by distillation, it appears that one of the most promising volatilization techniques is the vacuum distillation of the compounds or elements. This is particularly true if carrier-free separations are necessary, because wet chemical methods involve necessarily the addition of chemical reagents to the system. Additions of such chemicals add trace quantities of the inactive elements. Therfore, it is advantageous to have a separation system which requires contact of the carrier-free element with a minimum number of other elements. A simple one plate distillation with a furnace and one vapor collector in an evacuated system affords less carrier contamination of the separated radioisotope than most other separation techniques, except possibly the mass spectrographic method.

Additional emphasis could be placed on the use of compounds such as the solid chlorides in order to enhance selectivity of a particular separation. Since the carrier-free vacuum distillation technique can often be carried out very rapidly, its use for measuring the properties of short lived radionuclides should be given greater attention. 


\section{RADIOCHEMICAL DISTILLATION PROCEDURES.}

This section is a compilation of radiochemical separation procedures using distillation techniques. No attempt has been made to indicate in detail all of the distillation procedures which have been used for the various elements. If the element has been omitted no use of distillation technique was found in the literature. Selection of the included procedure has been based upon the author's evaluation of the description in the literature with particular regard to the supposed ease of carrying out the procedure. A number of the methods described here have been attempted by the author, and comments are given with these methods. Experimentalists who feel that their procedures should be included are invited to write to the author so that the method may be considered for a later edition.

Many of the distillation procedures for the elements have been included in the other National Academy of Sciences monographs dealing with radiochemistry of the individual elements. In order to reduce repetition, reference is made to these procedures in this monograph and it is suggested that the reader consult the pertinent monograph concerning details of the distillation procedure for the element of interest.

A. Hydrogen. These separations usually involve the conversion of tritiated compounds into tritium. The tritium is then passed into a counter for measurement of its radioactivity. Many of the techniques are reported in experiments done by geochemists who are interested in the tritium content of terrestial matter.

B. Rare Gases. He, Ne, Ar, $\mathrm{Kr}$, Xe, and $\mathrm{Rn}$ - Most of the separation procedures involve passing a carrier gas through a solution of the rare gases at room temperature. The rare gas is then collected on a cold trap or adsorbed on charcoal. This technique provides a very rapid separation as described in Monograph NAS-NS 3104 (30). A most comprehensive compilation of methods for the separation of the rare gases by 
distillation is given in Monograph NAS-NS 3025 (41).

C. Carbon, Nitrogen, and Oxygen. One of the most common methods for purifying these elements in organic compounds is the distillation technique. Since the number of applications far exceeds the scope of this monograph no attempt will be made to review this work. $\mathrm{c}^{14}$ can be counted with almost $100 \%$ efficiency by converting the $\mathrm{c}^{14}$ into a molecule that is used as a counting gas. $\mathrm{c}^{14}$ containing methane, acetylene and carbon dioxide have been successfully used as counting gases. The most familiar $\mathrm{C}^{14}$ dating technique utilizes such procedures. Nitrogen compounds are usually converted to $\mathrm{NH}_{3}$ for separation by distillation. A few specialized distillation procedures are detailed in Monograph NAS-NS 3019 (23), and NAS-NS 3104 (30).

D. Halogens. Chlorine, bromine, and lodine are often separated by the use of distillation. Distillation is used successfully for many short-1ived radioisotopes of these elements. (See Monographs NAS-NS 3005 (29), NAS $\rightarrow$ NS $3104(30)$ ). The usual procedure is to render the halogens non-volatile by oxidizing them to the +5 valence state. The more volatile components are then distilled and subsequently the halogen is reduced to the element for distillation. Quite often a carrier gas such as air or nitrogen is passed through the system to sweep out the halogen. E. Alkali Metals. Na, $\mathrm{K}, \mathrm{Rb}, \mathrm{Cs}, \mathrm{Fr}$. The handling of the elemental state of the alkali metals is difficult because of their reactivity with $\mathrm{O}_{2}$ and moisture. Most of the compounds of these elements are nonvolatile compared with the majority of those of the other elements. However, techniques have been used for the volatilization of francium which has been separated by carrying it on cesium silicotungstate, Monograph NAS-NS 3003 (24). The precipitate is converted to the perchlorate and the cesium and francium are removed as the elements by means of a "flash distillation," in which the precipitate on a platinum plate is touched with a gas-oxygen flame for a fraction of a second. The cesium and francium are collected on another platinum plate which 
is placed a few millimeters away. The platinum collector plate is then measured for radioactivity.

F. Silicon. The distillation procedures for silicon all utilize the fact that $\mathrm{SiF}_{4}$ is volatile (boiling point at $760 \mathrm{~mm}=-65^{\circ} \mathrm{C}$ ). Several detailed procedures are indicated in Monograph NAS-NS 3049 (35).

G. Phosphorous. A carrier-free distillation technique which was used successfully for $\mathrm{Sr}^{90}$ is described by Sherwin $(53,54)$ for $\mathrm{P}^{32}$. (See I below).

H. Sulfur. The usual techniques in which the sulfur is converted to $\mathrm{SO}_{2}$ or $\mathrm{H}_{2} \mathrm{~S}$ are applicable in a radiochemical separation. No detailed procedures were found in the literature.

I. Alkaline Earths, Rare Earths and Yttrium. The only description of a separation by distillation is given by Sherwin (53) where carrier-free $\mathrm{Sr}^{90}(28 \mathrm{y})$ is separated from $\mathrm{Y}^{90}$ (64h) by a technique which can best be described as a simple one plate vacuum distillation. The sample is heated on a tungsten filament. Both the collector and the filament can be adjusted from outside the evacuated chamber. The vapor is collected and measured with a Geiger counter while still in the apparatus. Since adequate shielding of the counter from the sample is provided in the evacuated chamber the system allows the measurement of short lived radioisotopes. The separation results in a decontamination factor of $10^{4}$ for $\mathrm{x}^{90}$ from $\mathrm{Sr}^{90}$.

J. Vanadium. A procedure is described in Monograph NAS-NS 3022 (6) where the volatile $\mathrm{VCl}_{4}$ and $\mathrm{TiCl}_{4}$ are distilled together from scandium chloride.

K. Chromium. A standard procedure for the distillation of chromium uses chromyl chloride $\left(\mathrm{CrO}_{2} \mathrm{Cl}_{2}\right)$. This radiochemical separation is done by predistilling potential contaminants such as $\mathrm{Sn}, \mathrm{Sb}$, As and $\mathrm{V}$ as their volatile halides. DeSoete reports the success of this procedure in Monograph NAS-NS 3007 (49). The contaminants are $\mathrm{Sn}(0.03 \%)$ and $V(0.02 \%)$ 


\section{Manganese. A unique method for the distillation of manganese}

utilizes the volatility of permanganic acid (48). The apparatus is similar to the distillation train described in Chapter II. The Isolation of Radiomanganese by Distillation as Permanganic Acid (48)

Procedure:

Introduce the aqueous solution into the distillation flask. Add $\mathrm{H}_{2} \mathrm{SO}_{4}(36 \mathrm{~N})$ to make $10 \mathrm{M}$ in sulfuric acid. If chemical yield is to be determined, add $0.5 \mathrm{mg}$ of manganese carrier. Add $1 \mathrm{gm} \mathrm{KIO}_{4}$ and heat the mixture using an iso-mantle or a metal bath. Bubble an inert gas through the solution to ensure regular boiling and keep the volume constant by the addition of $40 \% \mathrm{HNO}_{3}$, saturated with $\mathrm{KIO}_{4}$. Distil1 10 minutes. Boil the distillate with $250 \mathrm{mg} \mathrm{KIO}_{4}$ and dilute to $25 \mathrm{ml}$ for spectrophotometric determination of yield. (See Sandell, E. B., "Colorimetric Determinations of Traces of Metals," Interscience Publishers, Inc., New York, 1959, p. 608).

$\underline{\text { Remarks : }}$

Under the given conditions $\mathrm{Fe}, \mathrm{Co}, \mathrm{Cr}$ do not interfere. The procedure was tested with manganese concentrations ranging from carrier-free to $1 \mathrm{mg}$. The method was successfully used for the carrier-free separation of manganese from deuteron-irradiated iron cyclotron targets and gave also reproducible results in activation analysis of manganese in various biological materials. The recoveries were 60 to $90 \%$. M. Germanium, Arsenic, Antimony, and Tin. These elements are usually separated as a halide or as the hydride. Selected separation procedures are given in Monograph NAS-NS 3002 (4), NAS-NS 3033 (37), NAS-NS 3043 (38), NAS-NS 3023 (42) and (62). A history of the analytical separation of $\mathrm{As}, \mathrm{Sb}, \mathrm{Sn}$ by distillation of the halides is given by Scherrer (51).

An interesting analog of the zone melting technique is the "vapor zone refining" method described by $W$ isberg and Rossi (63). This method involves heating a tube of arsenic under vacuum. The heating element is slowly moved along the tube in a manner similar to that 
employed in zone melting. In this way impurities $\mathrm{Se}, \mathrm{Fe}, \mathrm{Al}$ and $\mathrm{Cu}$ are concentrated by a factor of three.

$\mathrm{Ge}^{73}$ (half-1ife 0.33 second) has been separated from $\mathrm{As}^{73}$ by a

"flash distillation" technique (14). This technique uses the basic idea of the single plate distillation, but the source is heated rapidly to its melting point with a large current surge. The distillation is completed in a fraction of a second, thereby allowing measurement of the short lived $\mathrm{Ge}^{73}$ which vaporizes and collects on a condenser plate situated a few millimeters from the source.

Successive Separation of Arsenic, Antimony and Tin (9)

Procedure :

The degree of separation of one milligram amount of each of the elements is measured by the use of radioisotopic tracers.

1. The final concentration of the solution after dissolving sample should be $11 \mathrm{~N}$ HC1.

2. The solution is then distilled in an all glass apparatus (e.g. similar to the distillation train described in Chapter II.) at $109^{\circ} \mathrm{C}$ while drawing anhydrous $\mathrm{CO}_{2}$ through the system. The vapor is collected in $11 \mathrm{~N} \mathrm{HC} 1$ (Note 1).

3. Without interrupting the heating add $7 \mathrm{ml}$ of concentrated $\mathrm{H}_{3} \mathrm{PO}_{4}$ (85) (Note 2) to the distillation flask. Heat this solution to $160^{\circ} \mathrm{C}$ and then slowly add $150 \mathrm{ml}$. of $11 \mathrm{~N} \mathrm{HC} 1$ while maintaining the temperature between $155-165^{\circ} \mathrm{C}$ (Note 3).

4. Lower the temperature to $140^{\circ} \mathrm{C}$ and add a solution of 3 parts $11 \mathrm{~N} \mathrm{HCl}$ to 1 part $40 \% \mathrm{HBr}$ by slow addition to the distillation flask so that the temperature is maintained at $140^{\circ} \mathrm{C}$ (Note 4 ).

Notes: 1. Quantitative separation of arsenic requires $40 \mathrm{~min}$.

2. The tin complexes with phosphate and does not disti11.

3. Quantitative separation of antimony is accomplished in $110 \mathrm{~min}$. 
4. Quantitative separation of tin is accomplished in $75 \mathrm{~min}$.

5. The chloride fractions can then be counted in solution or precipitated (e.g. as oxide, sulfide, etc.) and then counted.

N. Selenium and Tellurium. Selenium is routinely separated by distillation of the bromide using the wet-chemical distillation train method described in Chapter II. Tellurium bromide is volatile also, but careful distillation in the appropriate solution can separate the two. Most of the other volatile bromides and chlorides contaminate the separation. Detailed separation procedures are given in Monograph NASNS 3030 (32), NAS-NS 3038 (31).

\section{Carrier-Free Isolation of Selenium from Arsenic}

Procedure:

An interesting carrier-free procedure devised by Garrison, et al (19) separates the carrier-free radioisotope of selenium formed by the reaction $\mathrm{As}^{75}(\mathrm{~d}, 2 \mathrm{n}) \mathrm{Se}^{75}$.

1. Dissolve the arsenic metal in a minimum volume of aqua regia.

2. Add $12 \mathrm{~N} \mathrm{HCl}$ to remove the excess nitric acid and adjust the acidity to $3 \mathrm{~N} \mathrm{HCl}$.

3. Add $10 \mathrm{mg}$ of tellurous acid $\left(\mathrm{H}_{2} \mathrm{TeO}_{3}\right)$ and precipitate tellurium metal with $\mathrm{SO}_{2}$. (95\% of the $\mathrm{Se}^{75}$ is carried on this precipitate).

4. Dissolve the tellurium metal in $16 \mathrm{~N} \mathrm{HNO}_{3}$ and add arsenic chloride.

5. Reprecipitate the tellurium metal and filter to remove radioisotopes of arsenic produced by side reactions such as $A s^{75}$ (d,p) $A^{76}$.

6. Repeat steps 4 and 5 two more times.

7. Dissolve the tellurium metal in the minimum volume of $16 \mathrm{~N} \mathrm{HNO}_{3}$.

8. Distill in an all glass apparatus at $200^{\circ} \mathrm{C}$ (similar to train distillation described in Chapter II, after adding $14 \% \mathrm{HBr}$ using nitrogen gas carrier. The carrier-free selenium distills as the tetrabromide while the tellurium remains. 
o. Ruthenium, Osmium, Technetium, Rhenium. These elements have been grouped together because their separation by distillation is done by volatilizing the oxides, $\mathrm{RuO}_{4}, \mathrm{OsO}_{4}, \mathrm{Tc}_{2} \mathrm{O}_{7}$ and $\mathrm{Re}_{2} \mathrm{O}_{7}$. Selectivity in the separation can be affected by varying the composition of the distillation mixture and the composition of the solutions in which the vapor is collected.

Detailed separation techniques are given in the Monographs for ruthenium NAS-NS 3029 (65), osmium NAS-NS 3046 (34), technetium NAS-NS 3021 (1), and rhenium NAS-NS 3028 (33).

P. $\quad$ Rhodium and Silver. A carrier-free technique is described by Parker (47) for the separation of $\mathrm{Rh}^{103}$ from a ruthenium target. Yields of $20 \%$ were obtained in a one-minute distillation. The apparatus is similar to that using the simple one plate vacuum distillation technique described in Chapter II. The ruthenium target is placed on a tungsten filament, heated and rhodium is collected on Zapon film.

For silver, no aqueous solution techniques were found in the literature but several methods used distillation to separate the carrier-free radioisotope from a target material. The simple one plate distillation technique described in Chapter II was used in these procedures. The carrier-free technique used by Parker (47) for $\mathrm{Rh}^{103}$ was also used to separate $\mathrm{Ag}^{105}$ from a rhodium target. Procedure 1.

Separation of Silver from Palladium (12)

Reaction: $\mathrm{Pd}^{108}(\mathrm{n}, \gamma) \mathrm{Pd}^{109 \mathrm{~m}}(13.5 \mathrm{~h}) \quad .3-\mathrm{Ag}^{109 \mathrm{~m}}$ (39s).

The palladium foil is placed in a carbon furnace and heated by induction for three minutes at the temperatures indicated in the table below. The collected vapor which was invisible was placed in a scintillation well counter. The 39 second half-life of $\mathrm{Ag}^{109 \mathrm{~m}}$ was detected. In a short time the $\mathrm{Ag}^{109 \mathrm{~m}}$ reached secular equilibrium with the residual parenr pd ${ }^{109}$ which had volatilized with the carrier-free silver. This allowed tetermination of the $\mathrm{Pd}^{109}$ contamination in the 
$\mathrm{Ag}^{109 \mathrm{~m}}$ as follows:

\begin{tabular}{cccc}
\hline Temperature ${ }^{\circ} \mathrm{C}$ & Yield & $\begin{array}{c}\text { \%Contamination of } \\
109\end{array}$ & \multicolumn{2}{c}{ Decontamination } \\
& $\%$ & $\mathrm{Pd}^{109 \mathrm{~m} \mathrm{Ag}}$ & Factor for Pd \\
\hline 780 & 0.07 & 11 & $1.4 \times 10_{4}^{4}$ \\
880 & 0.14 & 3 & $2.3 \times 10^{4}$ \\
980 & 1 & 0.18 & $5.2 \times 10^{3}$ \\
\hline
\end{tabular}

Procedure 2.

Separation of Silver from Rhodium (57)

Reaction : $\mathrm{Rh}^{103}(\alpha, \mathrm{n}) \mathrm{Ag}^{106}$

1. Heat the rhodium metal target on a tantalum filament to approximately $2000^{\circ} \mathrm{C}$ in vacuurn (near the m.p. of rhodium) (Notes 1 and 2 ).

2. Collect the vaporized Ag on a cylindrical quartz catcher. (Note 3).

3. Dissolve the deposit in a few drops of concentrated $\mathrm{HNO}_{3}$ and one drop of concentrated HF. (Note 4).

4. Evaporate carefully to dryness and dissolve into $2 \mathrm{M} \mathrm{HCl}$.

5. Pass in $\mathrm{O}_{2}$ to oxidize any $\mathrm{Pd}$ to the +4 state.

6. Pass through a column ( $3 \mathrm{~mm}$ dia $\times 2 \mathrm{~cm}$ ) of Dowex 1 .

7. Dilute $\mathrm{Ag}$ with $10 \mathrm{M} \mathrm{HCl}$.

8. Dilute to $2 \mathrm{MHCl}$ and repeat the ion exchange step.

9. Evaporate to dryness, dissolve into a solution which contains

$2.5 \mathrm{ml}$ concentrated nitric acid, $2.5 \mathrm{ml}$ concentrated sulfuric acid and

$0.5 \mathrm{gm}$ of urea per $100 \mathrm{~m} 1$ of solution.

10. Electrolyze for two hours at 6 milliamperes current onto 0.010 dia. platinum wire. (Note 5).

Notes: 1 . When heated for only a few seconds almost $100 \%$ volatilization of $\mathrm{Ag}$ is obtained.

2. The tantalum filament is a $1 / 4^{\prime \prime}$ wide $\mathrm{x} 0.15^{\prime \prime}$ thick strip.

3. Some rhodium metal deposit was visible.

4. The rhodium metal did not dissolve appreciably.

5. The overall yield was $50 \%$. 


\section{Q. $\quad$ Cadmium}

\section{Procedure 1.}

\section{Electrolysis of Cadmium into Mercury Electrode and Distillation of}

Residue (12).

One milligram of cadmium is electrolyzed into a mercury cathode. The macro mercury is removed and the cadmium is distilled and collected. The following procedure was used:

1. Place $1 / 2$ gm. of mercury metal into the mercury cathode cell. (Note 1).

2. Place $1 \mathrm{mg}$. of cadmium as a carrier solution in the cell with trace amounts of the radioactive contaminating element (or with radioactive cadmium tracer added if yields are to be determined).

3. Add sufficient $1 \mathrm{~N} \mathrm{H}_{2} \mathrm{SO}_{4}$ to bring the total volume to approximately $1 \mathrm{~m} 1$.

4. Electrolyze the solution for 30 minutes at 6 volts.

5. Remove the electrolyte by means of a suction tube, and discard. Wash the mercury drop five times in distilled water and three times in acetone, and transfer to a pyrex tube. Evaporate the mercury. Transfer the residue to a carbon rod furnace and distill the cadmium between $160^{\circ}$ and $180^{\circ} \mathrm{C}$ at about one micron of pressure until no visible deposit forms when a fresh collecting surface is used after successive minute distillations.

6. The area on the Teflon film which contains the deposit is placed in a counting tube and counted in a scintillation well counter.

Notes: 1. Make a simple mercury cathode electrolysis cell by sealing a platinum wire into the bottom of a $5 \mathrm{ml}$. Pyrex test tube.

2. An experiment in order to evaluate the general procedure was done by attempting the separation of cadmium from the fission products of uranium. Uranyl acetate $(0.100 \mathrm{gm})$ was irradiated in the Phoenix reactor of the University of 
Michigan for 10 minutes at $10^{12}$ neutrons per $\mathrm{cm}^{2}$ per sec. Two hours after irradiation the solution was dissolved in $1 \mathrm{~N} \mathrm{H}_{2} \mathrm{SO}_{4}$ containing $1 \mathrm{mg}$. of cadmium carrier, and was electrolyzed for 30 minutes. This procedure removed $97 \%$ of the fission product activity from solution. After separating the macromercury and distilling the cadmium at $180^{\circ} \mathrm{C}$ in the vacuum distillation apparatus, detectable amounts of $\mathrm{Cd}^{115}$ and $\mathrm{Cd}^{117 \mathrm{~m}}$ were found. $(1000 \mathrm{c} / \mathrm{m}$ in the photopeak using a $3^{\prime \prime} \times 3^{\prime \prime}$ potassium iodide scintillator with a gamma ray spectrometer). Estimation of its purity indicated that the decontamination factor for the total activity in the fission products at 3 hours after fission was $10^{5}$.

3. The apparatus which was used is shown in Figure 1. A dessicator type of ground glass seal allows easy access to the distillation chamber. The furnace consists of a hollow carbon rod which is heated externally with induction coils. The Teflon film is wrapped around the cold finger.

4. Since $1 \mathrm{mg}$. of cadmium is used as a carrier, self absorption corrections will be an important consideration when doing absolute assay of the radioisotope.

Data from a detailed investigation of the separation are given in Table $I$.

Procedure 2.

Electrolysis of Cadmium into Copper Foil and Distillation from the Foil.

This procedure is given in Mongraph NAS-NS 3001 (11).

Procedure 3.

Separation of Cadmium from Silver (25).

Reaction: $\mathrm{Ag}^{107}(\mathrm{p}, 3 \mathrm{n}) \mathrm{Cd}^{105}$ (55m)

The silver target is heated in an evacuated quartz furnace to its melting point (about $960^{\circ} \mathrm{C}$ ). The carrier-free $\mathrm{Cd}^{105}$ is collected on a 
TABLE I

DECONTAMINATION FACTORS FOR ELECTROLYSIS OF CADMIUM INTO MERCURY AND THE DISTILLATION OF CADMIUM

\begin{tabular}{|c|c|c|c|c|}
\hline \multirow[b]{2}{*}{ Contaminant } & \multirow{2}{*}{$\begin{array}{c}\text { Amount } \\
(\mu \mathrm{g})\end{array}$} & \multicolumn{2}{|c|}{ Decontamination Factor } & \multirow[b]{2}{*}{ Overall } \\
\hline & & Electrolysis & Distillation & \\
\hline $\mathrm{Ag}^{110}$ & 8 & 2 & 10 & 20 \\
\hline $\mathrm{Ce}-\mathrm{Pr}^{144}$ & $C . F . * *$ & $1.4 \times 10^{3}$ & 20 & $3 \times 10^{4}$ \\
\hline $\mathrm{Cs}^{134}$ & 3 & $10^{3}$ & 20 & $2 \times 10^{4}$ \\
\hline $\mathrm{Co}^{60}$ & 7 & 2.5 & $10^{3}$ & $2.5 \times 10^{3}$ \\
\hline $\operatorname{Ir}^{192}$ & .05 & 4 & $\times 10^{2}$ & $10^{3}$ \\
\hline $\mathrm{Se}^{75}$ & 400 & 26 & 1.6 & 42 \\
\hline $\mathrm{Ru}^{106}$ & $3.6 *$ & 7 & $10^{3}$ & $7 \times 10^{3}$ \\
\hline $\mathrm{T} 1^{204}$ & 580 & 1.7 & 4.1 & 7 \\
\hline $\mathrm{Zn}^{65}$ & 50 & 1.6 & 20 & 32 \\
\hline $\mathrm{Zr}$ & 0.8 & 3 & 27 & 81 \\
\hline
\end{tabular}

*Solution of chloride converted to sulfate so that final concentration is $0.1 \mathrm{~N} \mathrm{H}_{2} \mathrm{SO}_{4}$.

$* *$ C. F. = Carrier - Free,

cd yield ( $1 \mathrm{mg}.) 93 \pm 2.5 \%$ error is standard deviation, 5 experiments.

$1 / 8^{\prime \prime} \mathrm{dia}$, aluminum disc $\left(1.7 \mathrm{mg} / \mathrm{cm}^{2}\right)$ or a tungsten wire $3 / 4^{\prime \prime} 1$ ong and $10 \mathrm{mils}$ in diameter. The degree of separation or yield was not discussed. Procedure 4.

Separation of Cadmium from Silver (16)

Reaction: $\operatorname{Ag}^{107}(\mathrm{p}, \mathrm{n}) \mathrm{Cd}^{107}(6.7 \mathrm{~h}) \stackrel{\beta+}{\longrightarrow} \mathrm{Ag}^{107 \mathrm{~m}}(44 \mathrm{~s})$

The silver target is heated on a tungsten filament, and the cadmium separated at $1400^{\circ} \mathrm{C}$ at a pressure of $10^{-5} \mathrm{~mm} \mathrm{Hg}$. The vapor is collected on silver (metal). Only $0.5 \%$ of $\mathrm{cd}^{107}$ was collected, but the collection efficiency for $\mathrm{Cd}^{107}$ was found to increase to $50 \%$ when the silver surface was freshly prepared in vacuum such that surface absorption of gases was minimized.

R. Indium

Separation of Indium from Tin (12)

Procedure:

Reaction: $\operatorname{Sn}^{112}(\mathrm{n}, \gamma) \mathrm{Sn}_{(112 \mathrm{~d}) \longrightarrow \mathrm{K}} \longrightarrow \operatorname{In}^{113 \mathrm{~m}}(1.7 \mathrm{~h})$ 
The tin metal in granular form was heated in a carbon furnace by induction in a vacuum of $5 \times 10^{-4} \mathrm{~mm} \mathrm{Hg}$ for 20 minutes at $270^{\circ} \mathrm{C}$. The In vapor was collected on Teflon 0.0001 inches thick stretched over a glass cold finger at liquid nitrogen temperature. (See Figure 1). A yield of $4.5 \%$ was obtained. When $0.001^{\prime \prime}$ thick tin foil is used, an In $113 \mathrm{~m}$ yield of $52 \%$ is obtained in 20 minutes. S. Gold. These methods utilize the single-plate distillation technique described in Chapter II. Au ${ }^{197}$ can be produced from platinum metal by the reaction $\mathrm{Pt}^{198}(\mathrm{n}, \gamma) \mathrm{Pt}_{(30 \mathrm{~m})}^{199} \stackrel{\beta \rightarrow}{\longrightarrow} \mathrm{Au}_{(3.2 \mathrm{~d})}^{199}$ (28). The platinum metal is heated almost to its melting point and the gold is almost completely volatilized. No intormation was given on the type of collector used.

Another application by Parker (47) volatilizes Au ${ }^{197}$ and $\mathrm{Au}^{195}$ from a platinum target. About $20 \%$ yield was obtained in a one-minute heating (no temperatures are indicated).

T. Mercury. Mercury is often distilled as a metal which has been obtained after a reduction step to gain added decontamination. Mercurous chloride has also been used in a distillation separation. Several of these procedures are discussed in Monographs NAS-NS 3104 (30), NAS-NS 3026 (50).

\section{Procedure 1.}

Steam-Distillation of Mercury (56).

Sion and Hoste have stated (56): "Steam distillation of mercury in the presence of a reducing agent was first proposed by Miller (W. L. Mi1ler \& L. E. Wachter: Ana1. Chem. 22, 1312, 1950), who claimed quantitative recoveries. In our procedure the reducing agent (either $\mathrm{SnSO}_{4}$ or $\mathrm{SnCl}_{2}$ ) was added in one step instead of dropwise. A microKjeldahl apparatus was used. The distillation process was monitored with $\mathrm{Hg}^{197}-\mathrm{Hg}^{203}$ tracer.

\section{Procedure:}

Introduce the solution into the micro-Kjeldahl apparatus and add 
$\mathrm{H}_{2} \mathrm{SO}_{4}$ to make the solution $0.5 \mathrm{~N}$ in acid. The total volume should not exceed $20 \mathrm{ml}$. Add $20 \mathrm{ml}$. $\mathrm{SnSO}_{4}$ or $\mathrm{SnCl}_{2}$ solution. Steam distillation is carried out from 15 to 20 minutes, the tip of the cooler plunging into $25 \mathrm{ml}$. of $\mathrm{a} \mathrm{H}_{2} \mathrm{SO}_{4}-\mathrm{KMnO}_{4}$ solution, cooled in ice water.

\section{Reagents:}

1. Conc. $\mathrm{H}_{2} \mathrm{SO}_{4}$ analytical grade.

2. Reducing agent :

a) $10 \mathrm{~g} \mathrm{SnSO}_{4}$ dissolved in $100 \mathrm{ml} \cdot \mathrm{H}_{2} \mathrm{O}+1 \mathrm{dr} 36 \mathrm{~N} \mathrm{H}_{2} \mathrm{SO}_{4}$; filter off residue;

b) $125 \mathrm{~g} \mathrm{SnCl}_{2} \cdot 2 \mathrm{H}_{2} \mathrm{O}$ are dissolved in $100 \mathrm{ml}$ of $12 \mathrm{~N} \mathrm{HCl}$ and diluted with water to $1000 \mathrm{ml}$;

3. $\mathrm{H}_{2} \mathrm{SO}_{4}-\mathrm{KMnO}_{4}$ mixture: $250 \mathrm{ml} 3.5 \mathrm{~N} \mathrm{H}_{2} \mathrm{SO}_{4}+250 \mathrm{ml} 0.8 \mathrm{~N} \mathrm{KMnO}_{4}$.

\section{Remarks :}

Method was tested with $\mathrm{Hg}$ carrier in the $0.2 \mu \mathrm{g}$ range. Quantitative results were obtained for up to $78 \mu \mathrm{g}$.

\section{Alternative procedure:}

Distillate is collected in two one $\mathrm{ml}$ portions of the $\mathrm{H}_{2} \mathrm{SO}_{4}$ mixture in 2 consecutive micro-traps."

\section{Procedure 2 .}

\section{Separation of Mercury Deposit from Metallic Copper (12)}

This method uses the we11-known fact that copper metal will reduce mercury onto its surface from aqueous solution. The copper strip is then heated to remove the mercury.

1. To a $50 \mathrm{ml}$ round bottom centrifuge cone, add carrier-free $\mathrm{Hg}^{203}$ tracer solution, in known amount for yield determination. If a decontamination factor is to be measured, use inactive mercury plus a radioisotopic tracer of the contaminant.

2. Add sufficient acid to bring total volume to $2 \mathrm{ml}$. of $0.15 \mathrm{~N} \mathrm{HNO}_{3}$.

3. Prepare an $8 \mathrm{mg}$. Cu foil, $0.5 \mathrm{~cm}^{2}$ (10 mils thick), by washing in $1 \mathrm{~N} \mathrm{HNO}_{3}$ to clean the surface; rinse with distilled water and add to the centrifuge cone. 
4. Stir slowly for about 20 minutes and wash six times with distilled water and once with acetone.

5. Transfer to a carbon rod furnace, and heat to $100^{\circ} \mathrm{C}$ for three minutes.

\section{TABLE II}

DECONTAMINATION FACTORS FOR THE SEPARATION OF MERCURY ONTO COPPER AND THE DISTILLATION OF MERCURY

\begin{tabular}{|c|c|c|c|c|}
\hline \multirow[b]{2}{*}{ Contaminant } & \multicolumn{4}{|c|}{ Decontamination Factors } \\
\hline & Amount $(\mu g)$ & Chemical Redn, & Distillation & Total \\
\hline$\overline{\mathrm{Ag}^{110}}$ & 200 & 1.2 & $2 \times 10^{4}$ & $2.4 \times 10^{4}$ \\
\hline $\mathrm{Ba}^{140}$ & C.F. & $3 \times 10^{2}\left(2.3 \times 10^{5}\right)$ & $3.3 \times 10^{2}$ & $10^{5}\left(7.6 \times 10^{7}\right)^{* 5}$ \\
\hline $\mathrm{Au}^{198}$ & 220 & 40 & $4 \times 10^{3}$ & $1.6 \times 10^{5 * 2}$ \\
\hline$C e^{144}-\operatorname{Pr}^{144}$ & C.F. & $1.2 \times 10^{3}$ & 2.3 & $2.8 \times 10^{3}$ \\
\hline$c d^{115 m}$ & 190 & $1.6 \times 10^{2}$ & $3.4 * 3$ & $5.4 \times 10^{2}$ \\
\hline $\mathrm{Co}^{60}$ & 7.4 & $10^{5}$ & 5 & $5 \times 10^{5}$ \\
\hline $\mathrm{Cr}^{51}$ & 5 & $2.5 \times 10^{3}$ & 6 & $1.5 \times 10^{4}$ \\
\hline $\mathrm{Cs}^{134}$ & 2.5 & $3 \times 10^{3}$ & 2.3 & $6.9 \times 10^{3}$ \\
\hline $\mathrm{Cu}^{64}$ & 65 & $1.2 \times 10^{2}$ & $1.4 \times 10^{2}$ & $1.7 \times 10^{4}$ \\
\hline $\operatorname{In}^{114}$ & 4.6 & $10^{5}\left(2 \times 10^{7}\right)^{* 4}$ & $10^{2}$ & $10^{7}\left(2 \times 10^{9}\right)$ \\
\hline $\operatorname{Ir}^{192}$ & 0.2 & $2 \times 10^{4}$ & 1.4 & $2.8 \times 10^{4}$ \\
\hline $\mathrm{Nb}^{95}$ & 8 & $3 \times 10^{3}$ & 10 & $3 \times 10^{4}$ \\
\hline $\mathrm{Pd}^{109}$ & 50 & 1.4 & $1.7 \times 10^{5}$ & $2.4 \times 10^{5}$ \\
\hline $\mathrm{Ru}^{106}$ & 2 & 32 & 350 & $1.1 \times 10^{4}$ \\
\hline $\mathrm{Se}^{75}$ & 3.5 & 6.5 & $2.8 \times 10^{3}$ & $1.8 \times 10^{4}$ \\
\hline $\mathrm{Sb}^{124}$ & 0.6 & $2.8 \times 10^{2}$ & 4.7 & $1.3 \times 10^{4}$ \\
\hline $\mathrm{Sn}^{113}$ & 500 & $1.3 \times 10^{3}$ & 10 & $1.3 \times 10^{4}$ \\
\hline $\mathrm{Ta}^{182}$ & 4 & - & - & $--* 1$ \\
\hline $\mathrm{Tl}^{204}$ & 400 & $4 \times 10^{4}$ & 2.5 & $10^{5}$ \\
\hline $\mathrm{zn}^{65}$ & 180 & $4.3 \times 10^{3}$ & 4.7 & $2 \times 10^{4}$ \\
\hline $\mathrm{zr}^{95}$ & 8 & $2.7 \times 10^{3}$ & 14 & $3.8 \times 10^{4}$ \\
\hline
\end{tabular}

*Notes (Table II):

1. Fluoride complexing agent for Ta interferes with the mercury yield.

2. Mercury comes off at $350^{\circ} \mathrm{C}$.

3. Mercury comes off at $220^{\circ} \mathrm{C}$.

4. Start with $5 \times 10^{6}$ and $\left(4 \times 10^{8}\right)$ (c/M resp.)

5. Start with $1.9 \times 10^{6}$ and $\left(1.9 \times 10^{9}\right)$ (c/M resp.) 
6. Collect the mercury on Teflon film. Cut out the area where collection occurs, and count in a scintillation well counter.

Notes: 1. The yield of the separation with $76 \mu \mathrm{gm}$ of $\mathrm{Hg}$ in $0.15 \mathrm{~N}$ $\mathrm{HNO}_{3}$ is $72 \pm 3 \%$. Error is standard deviation for 5 experiments.

2. Decontamination factors for a number of elements are 1isted in Table II.

Procedure 3.

Separation of Mercury from Gold (5)

Reaction: $\mathrm{Au}^{197}(\mathrm{n}, \gamma) \mathrm{Au}^{198} \stackrel{\mathrm{B}-}{\longrightarrow} \mathrm{Hg}^{198}(\mathrm{n}, \gamma) \mathrm{Hg}^{199}$ (42m)

Neutron-irradiated gold foil is heated in a vacuum at $10^{-5} \mathrm{~mm} \mathrm{Hg}$ at $900^{\circ} \mathrm{C}$ (quartz oven) for 5 to 6 hours. The $\mathrm{Hg}$ vapor is collected in a U-tube under liquid nitrogen. A $90 \%$ yield is obtained. Procedure 4.

Separation of Mercury from Gold (46)

This technique uses the one-plate distillation described in Chapter II with an apparatus very similar to that shown in Figure 1. Mylar is wrapped around a cold finger to act as a collecting surface. The charge is heated by a flame in a quartz tube under vacuum. U. Lead. Most of the distillation techniques are used for the separation of a rare gas precursor. Then the lead is separated by chemical methods from other daughter products of the rare gas radioisotope. (62). Carrier-Free Separation of $\mathrm{Pb}^{212}$ (ThB) from Parent $\mathrm{Th}^{232}$ (27) Procedure :

1. Place Dowex $50(8 x-100-200$ mesh) cation exchange resin in a Soxhlet extractor. Prepare the Dowex 50 by washing in $6 \mathrm{~N} \mathrm{HCl}$.

2. Reflux thorium nitrate in $1 \mathrm{MHNO}_{3}$. Notes 1 and 2.

3. Remove the ion exchange column $(22 \times 55 \mathrm{~mm})$ from the extractor and dilute the $\mathrm{Pb}^{212}$ with $1 \mathrm{~N} \mathrm{HCl}$. 
Notes: 1. Several nitric acid concentrations were tried. In $1 \mathrm{M}$ $\mathrm{HNO}_{3}$ a $40 \%$ yield is obtained.

2. Presumably $\mathrm{Rn}^{220}(55 \mathrm{sec})$ is volatilized and the daughter $\mathrm{Pb}^{212}$ is selectively retained on the ion exchange column.

v. Bismuth. Distillation is used mainly, as in the case of lead, to separate parent rare gas radioisotopes. (62).

W. Polonium. A complete description of the distillation techniques used for polonium are given in Monograph NAS-NS 3037 (13) and reference (61). The metal and various compounds such as the sulfide, diphenylcarbazide, and the diphenylthiocarbazide are volatile. Several of these have been used in separation procedures indicated in Monograph NAS-NS 3037 (13).

A technique for purifying polonium $\left(\mathrm{Po}^{211}\right)$ is to volatilize $\mathrm{At}^{211}$ from platinum while retaining $\mathrm{Po}^{211}(0.5 \mathrm{sec})$. (58). $\mathrm{X}$. Astatine. Since the chemistry of this element is quite complex the distillation technique has been used with more favorable results than those obtained with chemical methods in many separations. A very elaborate procedure is given in Monograph NAS-NS 3012 (2). Many of the older techniques are listed in (62). Others are listed in Monograph NAS-NS 3104 (30). A good discussion of the distillation technique for purification of astatine is given by Johnson et.al. (26). Y. Uranium. Volatilization of uranium as $U_{6}$ is a well-known separation procedure. Detailed procedures, particular studies on the decontamination factors, and interference effects are discussed in Monograph NAS-NS 3050 (20) and reference 52.

\section{Acknowledgement}

The author wishes to thank Dr. Nathan Ballou, chairman of the Subcommittee on Radiochemistry who has made constructive comments on the original manuscript. 


\section{REFERENCES}

[1] Anders, E., "The Radiochemistry of Technetium," Nuclear Science Series NAS-NS 3021, November 1960.

[2] Appleman, E. H., "The Radiochemistry of Astatine," Nuclear Science Series NAS-NS 3012, March 1960.

[3] Appleyard, E. T. S., Proc. Phys. Soc., London 49, 118-35 (1937).

[4] Beard, N. C., "The Radiochemistry of Arsenic," Nuclear Science Series NAS-NS 3002, January 1960.

[5] Beydon, J., J. Phys. Radium 19, Supp1. 144A (1958).

[6] Brownlee, J., "The Radiochemistry of Vanadium," Nuclear Science Series NAS-NS 3022, December 1960.

[7] Chemica1 Engineering News, March 6, 1961 (page 50).

[8] Cockroft, J. D., Proc. Roy. Soc. $\underline{119}, 293$ (1928).

[9] DeBruyne, P., Hoste, J., Bul1. Soc. Chim. Belg. 70, (5-6) 221-230 (1961).

[10] Devienne, F. M., J. Phys. Radium 13, 53 (1952); J. Phys. Radium 14, 251 (1953).

[11] DeVoe, J.R., "The Radiochemistry of Cadmium," Nuclear Science Series NAS-NS 3001, January 1960.

[12] DeVoe, J. R., U. S. Atomic Energy Commission Report, AECU-4610, December 1959.

[13] Figgins, P. E., "The Radiochemistry of Polonium," Nuclear Science Series NAS-NS 3037, January 1961.

[14] Finston, H., Miske1, J., Ann. Rev. Nuc1. Science 5, 269 (1958). 
[15] Fraser, R. G. J., "Molecular Rays," Cambridge University Press, Cambridge, England (1931).

[16] Frauenfelder, H., Huber, O., Preiswerk, P., Steffen, R., Helv. Phys. Acta 21, 197 (1948).

[17] Frauenfelder, H., Helv. Phys. Acta 23, 347 (1950).

[18] Frenke1, M., 3. Physik 26, 117 (1924).

[19] Garrison, W., Maxwe11, R., Hamilton, J., J. Chem. Phys. 18, 155 (1950).

[20] Gindler, J. E., "The Radiochemistry of Uranium," Nuclear Science Series NAS-NS 3050, March 1962.

[21] Holland, L., "Vacuum Deposition of Thin Films," Chapman \& Hall, London, 1952.

[22] Hoffman, J. I., and Lunde11, G. E. F., J. Research NBS 22, 465 (1939).

[23] Hudis, J., "The Radiochemistry of Carbon, Nitrogen and Oxygen," Nuclear Science Series NAS-NS 3019, December 1960.

[24] Hyde, E. K., "The Radiochemistry of Francium," Nuclear Science Series NAS-NS 3003, January 1960.

[25] Johnson, F. A., Can. J. Phys. 31, 1136 (1953).

[26] Johnson, G. L., Leininger, R. F., Segre, E., J. Chem. Phys. 17, 1 (1949).

[27] Kahn, M., Langhorst, A. L., J. Inorg. Nucl. Chem. 15, 384-5 (1960).

[28] Kidson, G. V., E1sdon, W. L., J. Appl. Radiation \& Isotopes $\underline{3}$,No. 3 252 (1958).

[29] Kleinberg, J., Cowan, G., "The Radiochemistry of Flourine, Chlorine, Bromine and Iodine," Nuclear Science Series NAS-NS 3005, January 1960.

[30] Kusaka, Y., Meinke, W. W., "Rapid Radiochemical Separations," Nuclear Science Series NAS-NS 3104, December 1961.

[31] Leddicotte, G. W., "The Radiochemistry of Tellurium," Nuclear Science Series NAS-NS 3038, July 1961. 
[32] Leddicotte, G. W., "The Radiochemistry of Selenium," Nuclear Science Series NAS-NS 3030, Apri1 1961.

[33] Leddicotte, G. W., "The Radiochemistry of Rhenium," Nuclear Science Series NAS-NS 3028, April 1961.

[34] Leddicotte, G. W., "The Radiochemistry of Osmium," Nuclear Science Series NAS-NS 3046, October 1961.

[35] Leddicotte, G. W., Mullens, W. J., "The Radiochemistry of Silicon," Nuclear Science Serius NAS-NS 3049, January 1962.

[36] Levinstein, H., J. Applied Physics 20, 306 (1949).

[37] Maeck, W. J., "The Radiochemistry of Antimony," Nuclear Science Series NAS-NS 3033, February 1961.

[38] Marinsky, J. A., "The Radiochemistry of Germanium," Nuclear Science Series NAS-NS 3043, Ju1y 1961.

[39] Melhuish, W. H., Nature 184, 1933 (1959).

[40] Merines, Jr., J. Phys. Rad. 17, No. 3, 308 (1956).

[41] Momyer, F. F., Jr., "The Radiochemistry of Rare Gases," Nuclear Science Series NAS-NS 3025, October 1960.

[42] Nervick, W. E., "The Radiochemistry of Tin," Nuclear Science Series NAS-NS 3023, October 1960.

[43] Olsen, L. O., Crittenden, E. C., Hoffman, R. W., Phys. Rev. 76, 1891 (1949).

[44] Parker, W. C., Nucl. Instr. 5, 142-7 (1959).

[45] Parker, W., DeCroes, M., Sevier, K., Jr., Nucl. Instr. I, 22-36 (1960).

[46] Parker, W. C., Nucl. Instr. 8 , 354 (1960).

[47] Parker, W., Grunditz, Y., Nuc1. Instr. 14, 71-5 (1961).

[48] Pijck, J., Hoste, J., "Separation of Radiomanganese by Distillation as Permanganic Acid," Anal. Chim. Acta 26, No. 6. 501 (1962).

[49] Pijck, J., "The Radiochemistry of Chromium," Nuclear Science Series NAS-NS 3007, January 1960, p. 23.

[50] Roesmer, J. and Kruger, P., "The Radiochemistry of Mercury," Nuclear Science Series NAS-NS 3026, December 1960. 
[51] Scherrer, J. A., J. Research NBS 21, 95 (1938).

[52] Schmets, J., Heremans, R., AEC-tr4880 (1961).

[53] Sherwin, C. W., Rev. Sci. Instr. 22, 339-41 (1951).

[54] Sherwin, C. W., Phys. Rev. 73, 216 (1948).

[55] Shibata, E., Saito, S., Nippen Kogoku Zasshi 80, 604-6 (1959).

[56] Sion, H., and Hoste, J., Laboratory for Analytical Chemistry, Ghent University (Belgium). (Private Communication).

[57] Smith, W. G., J. Inorg. Nuclear Chem. 17, 382-383 (1961).

[58] Spless, F. N., Phys. Rev. 94, 1292 (1954).

[59] Stah1, H. A., J. App1. Phys. 20, 1 (1949).

[60] Stockenda1, R., Bergkrist, K. E., Nuc1. Instr. 1, 53 (1957).

[61] Thomas, J. F., Sanborn, E. N., Muka1, M., Tebbens, B. D., Anal. Chem. 30, 1954 (1958).

[62] Wahl, A. C., and Ronner, N. A., "Radioactivity Applied to Chemistry"; Wiley \& Sons, New York (1951) pp 440-449.

[63] Weisberg, L. R., Rosi, F. D., Rev. Sci. Instr. 31, No. 2, 206 (1960).

[64] Widmer, H., Kirsch, J., Rev. Sci. Instr. 31, 791 (1960).

[65] Wyatt, E. I., Rickard, R. R., "The Radiochemistry of Ruthenium," NAS-NS 3029, February 1961.

[66] Yaffe, L.Ann. Rev. Nucl. Sci., 12, 153(1962). 


\section{MONOGRAPHS IN THE RADIOCHEMISTRY AND THE RADIOCHEMICAL TECHNIQUE SERIES}

Copies of the following monographs are available from the U. S. Department of Commerce, Office of Technical Services, Washington 25, D. C.

Aluminum and Gallium, NAS-NS-3032, $\$ 0.50$

Americium and Curium, NAS-NS-3006, $\$ 0.75$

Antimony, NAS-NS-3033, $\$ 0.50$

Applications of Computers to Nuclear and

Radiochemistry, NAS-NS-3107, $\$ 2.50$

Arsenic, NAS-NS-3002, $\$ 0.50$

Astatine, NAS-NS-3012, $\$ 0.50$

Barium, Calcium, and Strontium, NAS-NS$3010, \$ 1.25$

Beryllium, NAS-NS-3013, $\$ 0.75$

Cadmium, NAS-NS-3001, $\$ 0.75$

Carbon, Nitrogen, and Oxygen, NAS-NS$3019, \$ 0.50$

Cesium, NAS-NS-3035, $\$ 0.75$

Chromium, NAS-NS-3007, \$0.50

Cobalt, NAS-NS-3041, $\$ 1.00$

Copper, NAS-NS-3027, $\$ 0.75$

Detection and Measurement of Nuclear Radiation, NAS-NS-3105, $\$ 1.50$

Fluorine, Chlorine, Bromine, and lodine, NAS-NS-3005, $\$ 0.50$

Francium, NAS-NS-3003, $\$ 0.50$

Germanium, NAS-NS-3043, $\$ 0.50$

Gold, NAS-NS-3036, $\$ 0.50$

Indium, NAS-NS-3014, $\$ 0.50$

Iridium, NAS-NS-3045, \$0.50

Iron, NAS-NS-3017, $\$ 0.50$

Lead, NAS-NS-3040, \$1.75

Liquid-liquid Extraction with Highmolecular-weight Amines, NAS-NS-3101, $\$ 1.00$

Low-level Radiochemical Separations, NASNS-3103, $\$ 0.50$

Magnesium, NAS-NS-3024, $\$ 0.50$

Manganese, NAS-NS-3018, $\$ 0.50$

Mereury, NAS-NS-3026, $\$ 0.50$

Molybdenum, NAS-NS-3009, \$0.50

Nickel, NAS-NS-3051, $\$ 0.50$

Niobium and Tantalum, NAS-NS-3039, $\$ 0.75$
Osmium, NAS-NS-3046, $\$ 0.50$

Palladium, NAS-NS-3052, $\$ 0.75$

Paper Chromatographic and Electromigration Techniques in Radiochemistry, NASNS-3106, $\$ 0.50$

Phosphorus, NAS-NS-3056, \$0.50

Platinum, NAS-NS-3044, $\$ 0.50$

Polonium, NAS-NS-3037, \$0.75

Potassium, NAS-NS-3048, $\$ 0.50$

Protactinium, NAS-NS-3016, $\$ 1.00$

Rapid Radiochemical Separations, NAS-NS3104, \$1.25

Rare Earths - Scandium, Yttrium, and Actinium, NAS-NS-3020, $\$ 3.00$

Rare Gases, NAS-NS-3025, $\$ 0.75$

Rhenium, NAS-NS-3028, $\$ 0.50$

Rhodium, NAS-NS-3008, $\$ 0.50$

Rubidium, NAS-NS-3053, $\$ 0.50$

Ruthenium, NAS-NS-3029, $\$ 1.00$

Selenium, NAS-NS-3030, $\$ 0.50$

Separations by Solvent Extraction with Trin-octylphosphine Oxide, NAS-NS-3102, $\$ 0.75$

Silicon, NAS-NS-3049, \$0.50

Silver, NAS-NS-3047, $\$ 0.75$

Sodium, NAS-NS-3055, $\$ 0.50$

Sulfur, NAS-NS-3054, $\$ 0.50$

Technetium, NSA-NS-3021, \$0.50

Tellurium, NAS-NS-3038, $\$ 0.50$

Thorium, NAS-NS-3004, $\$ 0.75$

Tin, NAS-NS-3023, $\$ 0.75$

Titanium, NAS-NS-3034, $\$ 0.50$

Transcurium Elements, NAS-NS-3031, $\$ 0.50$

Tungsten, NAS-NS-3042, \$0.50

Uranium, NAS-NS-3050, $\$ 3.50$

Vanadium, NAS-NS-3022, $\$ 0.75$

Zine, NAS-NS-3015, $\$ 0.75$

Zirconium and Hafnium, NAS-NS-3011, $\$ 0.50$ 
